Portland State University

PDXScholar

$10-1-2012$

\title{
Measuring the Longitudinal Effects of Food Carbon Footprint Training on Consumers: Knowledge, Attitudes, and Behavioral Intentions
}

Robin Wikoff

Portland State University

Gretchen N. Rainbolt

University of Arizona

Wayne Wakeland

Portland State University, wakeland@pdx.edu

Follow this and additional works at: https://pdxscholar.library.pdx.edu/sysc_fac

Part of the Sustainability Commons, and the Transportation Commons Let us know how access to this document benefits you.

\section{Citation Details}

Wikoff, R., Rainbolt, G. N., \& Wakeland, W. (2012). Measuring the Longitudinal Effects of Food Carbon Footprint Training on Consumers: Knowledge, Attitudes, and Behavioral Intentions. Sustainability: The Journal of Record, 5(5), 317-322.

This Article is brought to you for free and open access. It has been accepted for inclusion in Systems Science Faculty Publications and Presentations by an authorized administrator of PDXScholar. Please contact us if we can make this document more accessible: pdxscholar@pdx.edu. 


\title{
Measuring the Longitudinal Effects of Food Carbon Footprint Training on Consumers: Knowledge, Attitudes, and Behavioral Intentions
}

\author{
Robin Wikoff, M.S., ${ }^{1}$, Gretchen Nurse Rainbolt, Ph.D., ${ }^{2}$ and Wayne Wakeland, Ph.D. ${ }^{1}$
}

\begin{abstract}
Although the supply chains through which foods are produced, processed, and transported can have a significant impact on carbon dioxide $\left(\mathrm{CO}_{2}\right)$ emissions, consumers are largely unaware of how their food choices may impact the environment. Based on a previous related study, ${ }^{1}$ we hypothesized that a web-based training process could increase consumer knowledge and perhaps influence consumer behavior longitudinally. To test this, food distribution networks were modeled and analyzed to determine $\mathrm{CO}_{2}$ footprints for a variety of foods, and a training process was designed to teach consumers about the $\mathrm{CO}_{2}$ emissions for different types of foods that are provided either locally or transported over long distances. The training allowed users to compare alternative choices for their daily food menu. Participants from two major urban universities were given an initial knowledge survey after which they participated in the online training program including the carbon footprint of foods associated with production, preparation, transportation, and storage. Later they took a post-treatment survey regarding their knowledge and their intentions to change their purchasing behavior in selecting foods. Follow-up surveys were administered after one month and after three months. Results indicate that participants' post-training knowledge increased and participants indicated that they intended to use the knowledge they gained to make more sustainable food choices. Additionally, participants partially retained the knowledge gained over time, maintained their intentions to change behavior, and followed through by implementing behavior change related to more sustainable food choices.
\end{abstract}

\section{Introduction}

Consumers are not likely to be aware of how their food choices impact the environment, the impact of which is often measured by the amount of carbon dioxide $\left(\mathrm{CO}_{2}\right)$ emitted or released during the production and transportation of the food. ${ }^{2}$ The environmental impact of food production varies considerably by food type as well as by supply chain logisticssuch as how far the food travels from producer to consumer, what transport methods are utilized, and how food is packaged and stored. ${ }^{3}$
A previous study on the impact of consumer awareness and attitudes regarding food carbon footprint ${ }^{1}$ suggested that training programs may increase consumer environmental self-efficacy, knowledge of food carbon footprint impact, and intentions to change food purchasing behaviors. Additionally, other research ${ }^{4}$ suggested that the use of carbon footprint measurements provides a starting point in a necessary discussion that will drive consumer awareness and behavioral change. Therefore, the food carbon footprint training tool that was developed in the previous study and was used in this study could lead consumers to think about the entire lifecycle of the product when making purchase decisions. This article describes the expanded follow-up study, using the same training tool.

\section{Food Carbon Footprint}

Fruits and vegetables travel over 1,500 miles, on average, within the United States, and half of the energy usage associated with food production and delivery is related to transportation.,6 A basic diet with imported ingredients

I Portland State University, Systems Science Graduate Program, Portland, Oregon.

${ }^{2}$ University of Arizona, Family and Consumer Sciences, Tucson, Arizona. 
can consume four times the fossil-fuel energy and emit four times the carbon dioxide, compared to domestically produced ingredients. ${ }^{7}$ Food production accounted for 17 percent of all fossil fuel usage in the United States in 2002, ${ }^{8}$ and food consumption accounts for nearly a third of our individual carbon footprints. ${ }^{9}$ These factors make it clear that individual consumers play a significant role in sustainability through their food choices.

\section{Impact of Changes in Individual Consumption Patterns}

Vermeir and Verbeke ${ }^{3}$ show that in order to enhance sustainable and ethical consumption, it is important to involve consumers, consider social norms, and enhance perceived availability of products. Several years later, Hume ${ }^{10}$ also found inconsistencies between consumer knowledge and action as well as between knowledge and intention to act. The previous related study, "Measuring the Effects of a Food Carbon Footprint Training and Tool on Consumers," however, demonstrated that training consumers on the environmental impacts of different food choices could potentially affect intentions for

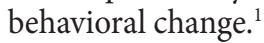

Appealing to consumers to be good ecological citizens is one of several powerful means of convincing people to buy locally grown food ${ }^{11}$ in order to reduce food-related carbon footprints. Sirieix ${ }^{2}$ studied consumer attitudes related to nonlocal foods and whether consumers factored origins (distance) of the food and consequent environmental pollution during transportation while making purchasing decisions. Similarly, Kriflik and Yeatman ${ }^{12}$ investigated consumer perceptions of environmental health while making food-related decisions and found that participants in their study desired more information about the food production processes.

\section{Relevant Web-Based Training Literature}

Kirkpatrick ${ }^{13}$ proposed a framework for evaluating training, which included four components: reactions, learning, behav- ior, and results. Of particular relevance for this study was the measurement of both learning (specific knowledge gains after the training) and behavior (the extent to which the knowledge gained in the training is transferred or used). This framework was utilized in this study as well, and training was used to provide knowledge with a goal of impacting the participants' sense of Environmental Self-Efficacy (ESE), i.e., the participant's belief that he/ she has the ability to impact the environment through behavior. ${ }^{14}$

Web-based studies allow researchers to control extraneous variables in the environment to maximize the validity of their causal conclusions and minimize the impact of potential confounding variables. Web-based tools can provide rapid, consistent feedback on performance to a greater extent than instructor-led learning techniques ${ }^{15}$ and can also allow participants to practice what they are learning. These features have been linked to better training outcomes with regard to learning and post-training behavioral change. ${ }^{16-18}$

\section{Research Hypotheses}

Building on the previous study, ${ }^{1}$ the research goals for this study were to enlarge the sample and extend the methodology to include a longitudinal component. Unlike the previous study, ${ }^{1}$ which was restricted to Oregon participants, the training instrument was used in two different geographic regions: Oregon and Colorado. We hypothesized that these two populations would have similar demographics and food values.

Similar to the previous study, ${ }^{1}$ we hypothesized that participants in both of our samples would show increases in knowledge of the carbon footprint of food choices and higher ESE immediately after the training. Participants in this study were also asked to respond to a survey instrument one month and three months after the training. Both this study and the previous study measured knowledge, ESE, and intentions to change foodpurchasing behavior. The current study additionally measured reported changes in food-purchasing behavior. Because these surveys measured similar outcomes, we further hypothesized that the initial increase of both knowledge and ESE directly after the training would decrease somewhat as time passed, but still remain significantly higher than the pre-training levels. Additionally, we hypothesized that participants would report significant behavior change, but that this change would decrease over time.

\section{Materials and Methods}

Participant Recruitment. Participants for the Portland State University (PSU) sample were recruited from undergraduate and graduate classrooms in October 2009, with a 32 percent response rate. The original number of study participants, 221, was reduced to 216 due to missing or incomplete responses. Those who completed the initial survey were entered into a raffle with a chance to win one of two $\$ 50$ cash cards, and in some cases they were given extra credit by their faculty.

Participants for the Colorado State University (CSU) sample were enrolled in an Introductory Psychology class in October 2009 and participated to fulfill their experimental participation requirement, with a response rate of 93 percent. The original number of study participants, 408 , was reduced to 371 due to missing or incomplete responses.

For the longitudinal phase, students who completed the one-month and threemonth follow-up surveys were entered into a raffle for $\$ 25$ and $\$ 50$ cash cards, respectively. Response rates for the onemonth survey were 75 percent for CSU and 33 percent for PSU. For the threemonth follow-up survey, response rates were 20 percent for CSU $(N=56)$ and 40 percent for PSU $(N=26)$.

The data were collected via web-based survey. The initial phase of the study took participants an average of 30 minutes to complete. The longitudinal data was collected by sending participants e-mails with instructions, a hyperlink to the relevant web-based survey, and contact information for questions and concerns. The follow-up longitudinal surveys took participants an average of 10 minutes to complete.

CarbonScope $e^{\mathrm{rm}}$ Training Tool. This study focused on the impact of using the CarbonScope ${ }^{\mathrm{TM}}$ training process to teach par- 
ticipants about the carbon footprints of potential food choices. In particular, this study was interested in longitudinal effects of this training on participants' knowledge, ESE, and behavior change that have not been previously assessed. Detailed information about this tool can be found in the previous referenced study. ${ }^{1}$ This tool acts as an interactive online tutorial in which participants are able to navigate a system that provides data about the calculation of carbon footprints for a variety of foods. The CarbonScope training guided participants through three scenarios comparing food carbon footprints among different types of food: plant-based vs. animal-based foods, regional vs. global, and raw vs. processed foods (see Figure 1).
Consumer Motivation. Participant motivation related to food purchase behavior was accounted for by asking participants to agree or disagree on a fivepoint scale to a series of attributes and values related to food. For example: I make purchases based on convenience, or I make purchases based on being fair trade. Other attributes included were taste, health, cost, ethics, social responsibility, sustainable, organic, local, humane treatment, and non-GMO. This was recorded only on the pre-survey measurement $\left(\mathrm{T}_{1}\right)$.

Knowledge. The knowledge survey instrument included seven questions related to general knowledge of food carbon foot-

\section{Raw versus Processed Foods}

\section{Let's compare raw foods to processed foods.}

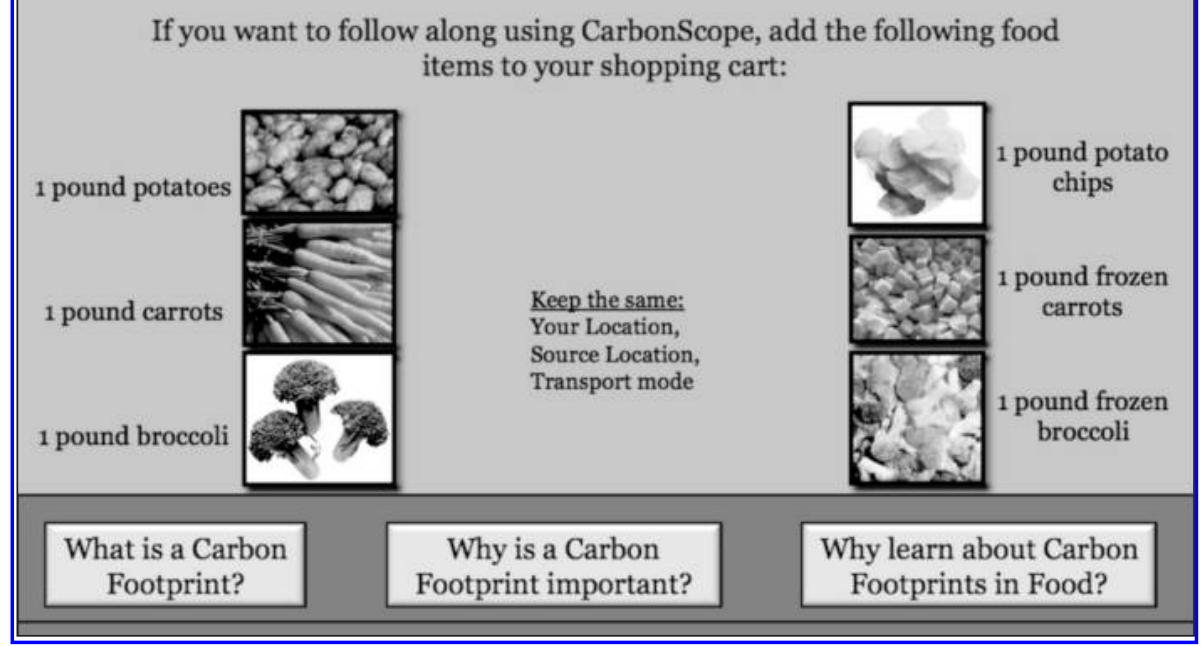

FIG. 1. Sample scenario given to participants in Food Carbon Footprint training.

Training success was measured through a standard pre-survey, training, and post-survey design, with a longitudinal phase that included one-month and three-month follow-up surveys. Data were collected via surveys at four different times: pre-survey $\left(\mathrm{T}_{1}\right)$, post-survey $\left(\mathrm{T}_{2}\right)$, one-month $\left(\mathrm{T}_{3}\right)$, and three-month $\left(\mathrm{T}_{4}\right)$. Appendix A contains more detailed information about the individual questions for outcome measurement, but in general the following constructs were measured:

Demographics. Demographic information that was collected and used in the analyses was gender, ethnicity, and education. This was recorded only on the presurvey measurement $\left(\mathrm{T}_{1}\right)$. prints, and was administered at all four time points $\left(\mathrm{T}_{1}-\mathrm{T}_{4}\right)$. An example of a question was: Which of the following has the smaller carbon footprint: a.) 1 pound of turkey, b.) 1 pound of bananas, c.) 1 pound of tuna, or d.) 1 pound of beef. Participant responses were summed to form a composite knowledge variable for each participant at each time point, with a higher value indicating increased knowledge of food carbon footprints, ranging from 7 to 0 .

Environmental Self-Efficacy (ESE). At all four time points $\left(\mathrm{T}_{1}-\mathrm{T}_{4}\right)$, the survey also included four items to assess the ESE, which explored the degree of difference that participants felt they could make regarding environmental problems, using the same five-point scale (see Consumer Motivation). One example of an item is: Changes in my behavior can help the Earth. Factor analyses at each time point confirmed that the items could form a coherent factor (e.g., $\mathrm{T}_{1}$, PSU $\alpha=.86$ ). All Cronbach's alpha ranged from .82 to .86 .

Behavior/Behavioral Intention. All surveys after the training included three items to assess the participant's intentions to share and apply the knowledge gained from the training $\left(\mathrm{T}_{2}-\mathrm{T}_{4}\right)$. In the longitudinal surveys $\left(\mathrm{T}_{3}-\mathrm{T}_{4}\right)$, this outcome was changed to measure actual behavior, not just behavior intention. Again, factor analyses were used to confirm that these questions formed a coherent factor at each time point. For example, at $\mathrm{T}_{2}$ the PSU a $=.87$ and the CSU sample $a=.89$. All Cronbach's alpha for different time points ranged from .87 to .89 .

Procedure. The pre-training survey $\left(\mathrm{T}_{1}\right)$ included demographics, knowledge questions, consumer motivations/values, and ESE measures.

After the pre-survey and training $\left(\mathrm{T}_{1}\right)$, the participants took the post-training survey $\left(\mathrm{T}_{2}\right)$ to retest their knowledge about food carbon footprints and their sense of Environmental Self-Efficacy, and to assess their intentions to use the knowledge gained to change their food selection behaviors.

One month after the training, a follow-up survey was made available $\left(\mathrm{T}_{3}\right)$. This survey retested the participants' knowledge of food carbon footprints, environmental self-efficacy, and intentions to change food choice behaviors. It also asked about actual behavior change related to food choice behaviors. Three months after the training was complete, a second identical follow-up survey was made available $\left(\mathrm{T}_{4}\right)$.

\section{Results}

Demographics, consumer motivations, and values were compared in order to identify any potential differences in the samples. A $t$ test indicated that the age of participants in the PSU and CSU samples were different $(p<.01)$, with the average age being 27 for PSU and 19 for CSU participants. Contingency table chi-square tests indicated that while gender, taste preferences, and attitudes toward sustain- 
ability were not significantly different in the two samples, ethnicity and education had statistically significant differences, as did attitudes toward convenience, health, cost, ethics or morals, social responsibility, organic, fair trade, locally produced, humanely treated, and non-GMO foods. Since a majority of the demographic and motivational variables were significantly different between samples, we decided to keep the samples split for main analyses. For clarification, the main analyses are detailed in Table 1.
In the longitudinal component of the study, a series of one-way repeated-measures analyses of variance were conducted to evaluate the change in Knowledge ( $\left.\mathrm{T}_{1}-\mathrm{T}_{4}\right)$, ESE ( $\mathrm{T}_{1}$ $\mathrm{T}_{4}$ ), and Intentions/Behaviors $\left(\mathrm{T}_{2}-\mathrm{T}_{4}\right)$ over time. To maximize sample sizes and minimize the effect of attrition, separate analyses of variance (ANOVAs) were run with analysis: 1.) $\mathrm{T}_{1}, \mathrm{~T}_{2}$, and $\mathrm{T}_{3}(N=276)$ and 2.) $\mathrm{T}_{1}, \mathrm{~T}_{2}$, $\mathrm{T}_{3}$, and $\mathrm{T}_{4}(N=56)$.

For the Knowledge ANOVAs, all omnibus tests were significant $(p<.001)$, and there

\begin{tabular}{|c|c|c|c|c|c|c|c|}
\hline DV & Sample & Statistical test & $\mathrm{N}$ & $T_{1}$ & $T_{2}$ & $\mathrm{~T}_{3}$ & $\mathrm{~T}_{4}$ \\
\hline \multirow{6}{*}{ Knowledge } & \multirow{3}{*}{ CSU } & $t$ test & 371 & $\mathrm{X}$ & $\mathrm{x}$ & & \\
\hline & & One-Way Repeated Measures ANOVA & 276 & $\mathrm{X}$ & $\mathrm{X}$ & $\mathrm{X}$ & \\
\hline & & One-Way Repeated Measures ANOVA & 56 & $\mathrm{x}$ & $x$ & $\mathrm{x}$ & $\mathrm{x}$ \\
\hline & \multirow{3}{*}{ PSU } & $t$ test & 216 & $\mathrm{X}$ & $\mathrm{X}$ & & \\
\hline & & One-Way Repeated Measures ANOVA & 72 & $\mathrm{X}$ & $\mathrm{X}$ & $\mathrm{X}$ & \\
\hline & & One-Way Repeated Measures ANOVA & 29 & $\mathrm{x}$ & $\mathrm{x}$ & $\mathrm{x}$ & $\mathrm{X}$ \\
\hline \multirow{6}{*}{ ESE } & \multirow{3}{*}{ CSU } & $t$ test & 371 & $\mathrm{X}$ & $\mathrm{X}$ & & \\
\hline & & One-Way Repeated Measures ANOVA & 276 & $\mathrm{X}$ & $\mathrm{X}$ & $\mathrm{X}$ & \\
\hline & & One-Way Repeated Measures ANOVA & 56 & $\mathrm{X}$ & $\mathrm{x}$ & $\mathrm{X}$ & $\mathrm{X}$ \\
\hline & \multirow{3}{*}{ PSU } & $t$ test & 216 & $\mathrm{X}$ & $\mathrm{x}$ & & \\
\hline & & One-Way Repeated Measures ANOVA & 72 & $\mathrm{X}$ & $\mathrm{X}$ & $\mathrm{X}$ & \\
\hline & & One-Way Repeated Measures ANOVA & 29 & $\mathrm{X}$ & $\mathrm{x}$ & $\mathrm{X}$ & $\mathrm{X}$ \\
\hline \multirow{4}{*}{ Intentions / Behaviors } & \multirow{2}{*}{ CSU } & $t$ test & 276 & & $\mathrm{X}$ & $\mathrm{x}$ & \\
\hline & & One-Way Repeated Measures ANOVA & 56 & & $\mathrm{X}$ & $\mathrm{X}$ & $\mathrm{X}$ \\
\hline & \multirow{2}{*}{ PSU } & $t$ test & 72 & & $\mathrm{x}$ & $\mathrm{X}$ & \\
\hline & & One-Way Repeated Measures ANOVA & 29 & & $\mathrm{X}$ & $\mathrm{X}$ & $\mathrm{X}$ \\
\hline
\end{tabular}

Table 1. Summary of statistical tests, dependent variables, sample sizes, and time points used.

There are four time points used in the analyses: pre-training $\left(\mathrm{T}_{1}\right)$, post-training $\left(\mathrm{T}_{2}\right)$, one month after the training $\left(\mathrm{T}_{3}\right)$, and three months after the training $\left(\mathrm{T}_{4}^{3}\right)$. $T$ tests were run to test the differences in the Knowledge and ESE measures of participants at $\mathrm{T}_{1}$ and $\mathrm{T}_{2}$ (pre- and post-training). In both samples there was a statistically significant increase in Knowledge ( $p$ $<.001$ ) from $\mathrm{T}_{1}$ to $\mathrm{T}_{2}$, from an average of 4.51 to 5.18 for PSU, and from 4.19 to 5.04 for CSU.

In the CSU sample, there was a statistically significant increase in Environmental Self-Efficacy (ESE) $(p<.001)$, from 3.95 to 3.96, but in the PSU sample, there was no statistically significant difference in ESE after the training. Although the change after the training for the PSU sample was not statistically significant, the mean values of the ESE measures both before and after the training were higher for the PSU sample than the comparable measures for the CSU sample. were significant linear, quadratic, and cubic trends for both samples $(p<.05)$. The linear trends indicated that mean Knowledge scores increased with time. The quadratic trends indicated that Knowledge was low at $\mathrm{T}_{1}$, highest at $\mathrm{T}_{2}$, and lower again at $\mathrm{T}_{3}$, but still remained higher than $\mathrm{T}_{1}$.

In the second analysis including $\mathrm{T}_{4}$, the quadratic and cubic trends indicated that although mean Knowledge scores increased at $\mathrm{T}_{2}$, and remained relatively high at $\mathrm{T}_{3}$, difference in Knowledge at $\mathrm{T}_{4}$ compared to $\mathrm{T}_{1}$ was not significant.

For the Environmental Self-Efficacy (ESE) ANOVAs, not all omnibus tests were significant. In the PSU sample, in the larger sample $\left(\mathrm{T}_{1}-\mathrm{T}_{3}\right)$, the omnibus ANOVA was not significant, indicating that ESE did not change across three time points. In the CSU sample, in the larger sample $\left(\mathrm{T}_{1}-\mathrm{T}_{3}\right)$, the omnibus tests were significant $(p<.001)$. Follow-up polynomial contrasts showed significant linear and

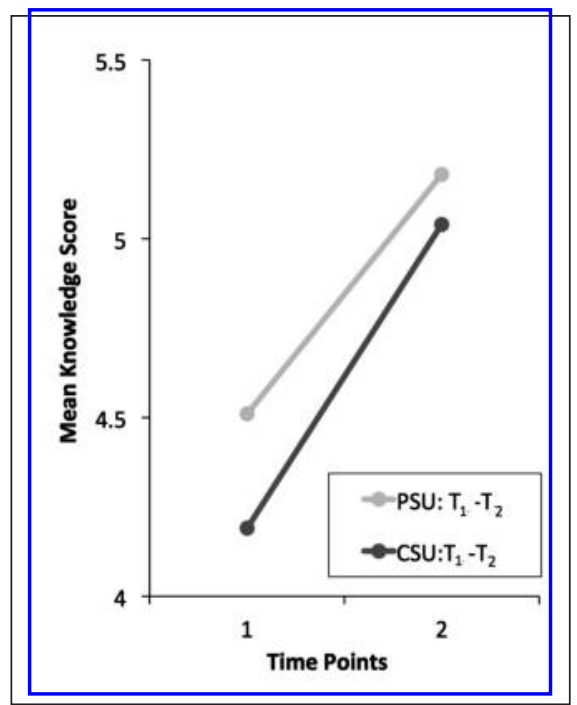

FIG. 2. Knowledge scores for both samples from $\mathrm{T}_{1}$ to $\mathrm{T}_{2}$ : $\mathrm{PSU} N=216, \mathrm{CSU} N=371$.

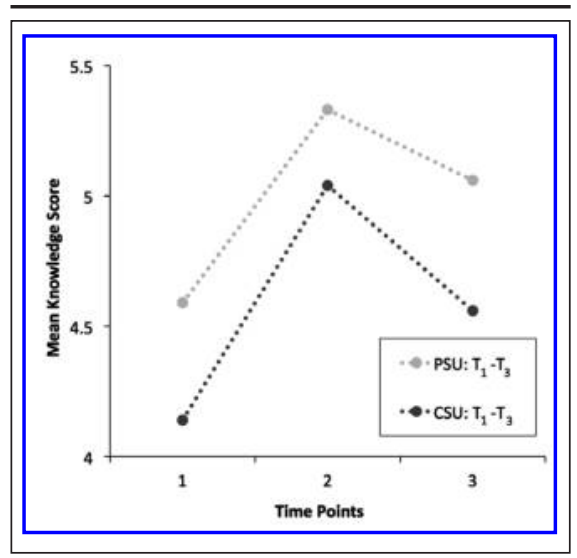

FIG.3. Knowledge scores for both samples from $\mathrm{T}_{1}$ to $\mathrm{T}_{3}$ : $\mathrm{PSU} N=72, \mathrm{CSU} N=276$.

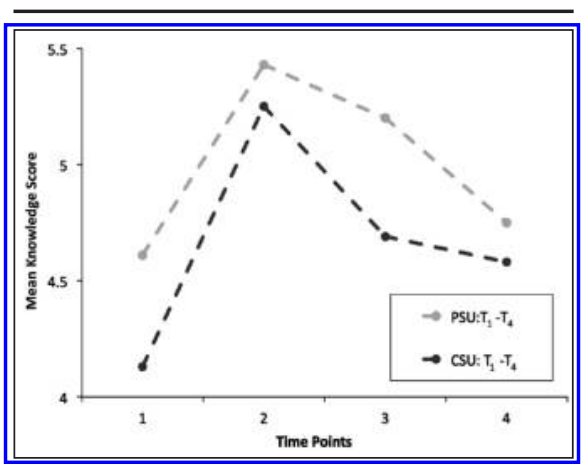

FIG. 4. Knowledge scores for both samples from $\mathrm{T}_{1}$ to $\mathrm{T}_{4}$ : PSU $N=29, \mathrm{CSU} N=56$.

quadratic trends $(p<.01)$, indicating that there was a significant increase in ESE at $\mathrm{T}_{2}$ compared to $\mathrm{T}_{1}$, and that although ESE decreased at $\mathrm{T}_{3}$, the ESE mean was still significantly higher at $\mathrm{T}_{3}$ compared to $\mathrm{T}_{1}$. In both PSU and CSU smaller samples (for which $\mathrm{T}_{4}$ values were available), the 
omnibus ANOVAs were not significant, indicating non-significant changes in ESE across the four time points.

A $t$ test and ANOVA were used to test the differences in the Intentions/Behaviors (I/B) measure of participants at $\mathrm{T}_{2}$ and at $\mathrm{T}_{3}$, and also for $\mathrm{T}_{2}, \mathrm{~T}_{3}$, and $\mathrm{T}_{4}$, separately for the PSU sample and the CSU sample. For both CSU and PSU there were statistically significant decreases in Intentions/ Behaviors at $\mathrm{T}_{3}$ compared to $\mathrm{T}_{2}$. For the ANOVA, all omnibus tests were significant $(p<.01)$. Follow-up polynomial contrasts showed significant linear and quadratic trends for both samples $(p<.05)$. The linear trend suggests that mean $\mathrm{I} / \mathrm{B}$ scores decreased with time. Both samples show a significant decrease in $\mathrm{I} / \mathrm{B}$ from $\mathrm{T}_{2}$ to $\mathrm{T}_{3}$, and in the PSU sample, I/B again significantly decreased from $T_{3}$ to $T_{4}$, while in the CSU sample, there was no significant change in from $\mathrm{T}_{3}$ to $\mathrm{T}_{4}$.

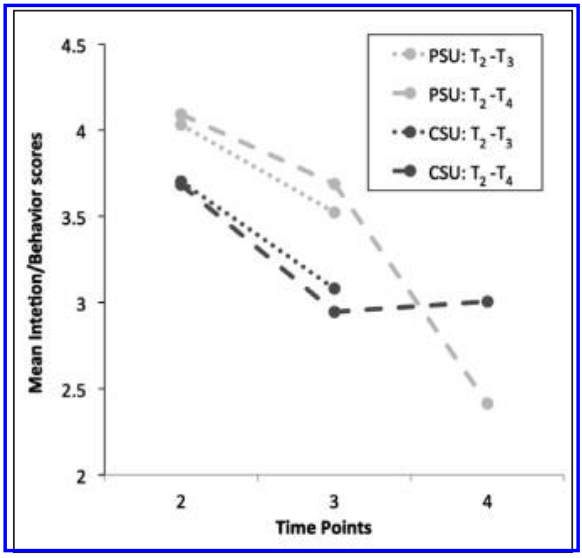

FIG. 5. Intention/Behaviors scores for both samples, for larger sample $\mathrm{T}_{2}$ to $\mathrm{T}_{3^{\prime}}$ and smaller sample $\mathrm{T}_{2}$ to $\mathrm{T}_{4}$

\section{Discussion}

The food carbon footprint training tool was tested in two separate geographic regions and, after $t$ tests and chi-square contingency tests, these two samples were found not to be similar in terms of demographics or food-choice-related values, which disconfirmed our hypothesis that the samples would be similar. While this lowered the sample size for each statistical test, having two distinct samples provided an opportunity to test the generalizability of the training tool, in addition to testing the longitudinal effects of the training.
"In this study, which, as referenced, is an expansion of 'Measuring the Effects of a Food Carbon Footprint Training and Tool on Consumers,' ${ }^{\prime}$ participants in both samples showed increased knowledge immediately after the training, and, although knowledge decreased one month and again three months after the training," participants showed overall retention of knowledge from the training.

Environmental Self-Efficacy (ESE) was hypothesized to increase after the training, but for the PSU sample, this proved to be incorrect. There was no significant change in ESE for the PSU participants after the training, one month later, and three months later. This may be due to the fact that the PSU participants had a very high degree of ESE prior to the training. For the CSU participants, there was a significant increase in their ESE after the training, which decreased after one month and further decreased three months after the training. Nevertheless, it remained higher after three months than before the training, indicating a lasting impact of the training on ESE.

The Intentions/Behaviors of the participants to use the knowledge gathered to influence their food choices decreased in both samples, as hypothesized, one month after the training compared to immediately after the training. In the CSU sample, the Intentions/Behaviors decreased more sharply at first, with lesser reduction at three months. The PSU participants' Intentions/Behaviors showed a more gradual decrease at one month and a sharp decrease at three months, indicating that their training had a stronger initial impact than the CSU sample, but perhaps less residual impact over a longer time period.

Although the main purpose of the project was to use the CarbonScope training tool to impact participants' understanding, perceptions, and behaviors about food purchasing over a longer duration of time than previous research, we are aware that there are limitations inherent in our ability to maintain sample size. Attrition rates were relatively high, limiting the statistical testing capabilities as well as strength of results-especially at the month three time point. Future research should address this both methodologically as well as statistically (with more sophisticated statistical tools). Additional limitations include the student population used for the sample selections. Despite the accessibility, the responses to the training by these samples may be different from a larger, more general population sample.

Further research may include exploration of the relationship between ESE and Intentions/Behaviors, since it is interesting that in the CSU sample, participants seemed to benefit from the training more in terms of ESE, and showed the least decline in intentions to use the information to change their food choices and in actual behavioral changes in their food choices in the long run. In the future, it may be useful to consider Analysis of Covariance to control for demographic differences in the samples.

To conclude, the Food Carbon training seems to be able to increase knowledge about the carbon impacts of common food choices, increase the ESE of participants with a low sense of ESE, and to a lesser degree, to motivate people to change their food choices in favor of more sustainable options.

\section{Acknowledgments}

We would like to thank the faculty of Portland State University and Colorado State University for facilitating their students' participation in this study.

\section{Author Disclosure Statement}

No competing financial interests exist.

\section{References}

1. Wakeland W, Venkat K, and Sears L. Measuring the effects of a food carbon footprint training and tool on consumers: Knowledge, attitudes, and behavioral intentions. Sustain J Record 2009;2(1):4552 .

2. Sirieix L, Grolleau G, and Schaer B. Do consumers care about food miles? An empirical analysis in France. Int J Consumer Stud 2008;32(5):508-515.

3. Vermeir I, and Verbeke W. Sustainable food consumption: Exploring the consumer "attitude-behavioral intention" gap. I Agric Environ Ethics 2006;19:169194. 
4. Weidema BP, Thrane M, Christensen $\mathrm{P}$, et al. Carbon footprint: A catalyst for life cycle assessment? Indus Ecol 2008;12(1):3-6.

5. Pirog R, Van Pelt T, Enshayan K, et al. Food, Fuel and Freeways: An Iowa Perspective on How Far Food Travels, Fuel Usage, and Greenhouse Gas Emissions. Leopold Center for Sustainable Agriculture, Iowa State University, Ames, Iowa, 2001.

6. Piecyk MI, and McKinnon AC. Forecasting the carbon footprint of road freight transport in 2020. Int J Produc Econ 2010;128:31-42.

7. Halweil B. Home Grown: The Case for Local Food in a Global Market. Worldwatch Institute, Washington, DC, 2002.

8. Eshel G, and Martin PA. Diet, energy, and global warming. Earth Interact 2005;10(9):1-17.

9. Jones CM, and Kammen DM. Quantifying carbon footprint reduction opportunities for U.S. households and communities.
Environ Sci Technol 2011;45:4088-4095. 10. Hume M. Compassion without action: Examining the young consumers' consumption and attitude to sustainable consumption. L World Bus 2010;45(4):385394.

11. Seyfang G. Ecological citizenship and sustainable consumption: Examining local organic food networks. J Rural Stud 2006;22:383-395.

12. Kriflik LS, and Yeatman H. Food scares and sustainability: A consumer perspective. Health Risk Soc 2005;7(1):11-24. 13. Kirkpatrick DL. Techniques for evaluating training programs. J ASTD 1959;13:3-9.

14. Denious J. Evaluation of Colorado Youth Corps: Crew-based employment and training programs for young people. Colorado Youth Corps Association, Denver, 2003.

15. Keys B, and Wolfe J. The role of management games and simulations in educa- tion and research. J Manage 1990;16:307336.

16. Chhokar JS, and Wallin JA. A field study of the effect of feedback frequency on performance. J Appl Psychol 1984;69(3):524-530.

17. Machin MA. Planning, managing, and optimizing transfer of training. In Kraiger $\mathrm{K}$ (ed.), Creating, Implementing and Managing Effective Training and Development. Jossey-Bass, San Francisco, 2002, pp. 263301.

18. Stajkovic AD, and Luthans F. Behavioral management and task performance in organizations: Conceptual background, meta-analysis, and test of alternative models. Personnel Psychol 2006;56:155-194.

Address correspondence to:

Robin Wikoff, M.S.

P.O. Box 751

Portland, OR 97207-0751

E-mail:RFenske@pdx.edu

\section{Appendix A}

\section{Survey Instrument}

Across the surveys, some sets of questions were asked multiple times, such as Knowledge, ESE, and Intentions/Behaviors questions, while others, such as Demographics questions, were only asked in the Pre-Training Survey. Each survey is summarized below:

\section{Pre-Training Survey}

- Demographics Questions

- Knowledge Questions

- Environmental Self-Efficacy Questions

\section{One Month Follow-Up Survey}

- Knowledge Questions

- Environmental Self-Efficacy Questions

- Behaviors that transfers knowledge from the training Questions

\author{
Post-Training Survey \\ - Reactions to Training Questions \\ - Knowledge Questions \\ - Environmental Self-Efficacy Questions \\ - Intentions to transfer knowledge from the training to behavior Questions \\ Three Month Follow-Up Survey \\ - Knowledge Questions \\ - Environmental Self-Efficacy Questions \\ - Behaviors that transfers knowledge from the training Questions
}

Demographics Questions included questions on age, ethnicity, region of residency, education, foods the participant intentionally refrained from consuming, and food purchasing motivations.

Knowledge Questions asked participants questions about carbon footprints and food related to three different scenarios or topics: Food Production (animal-based vs. plant-based foods), Food Transportation (distance and mode of transport), and Food Processing (processed vs. raw foods). For example: Which of the following food groups generally has the biggest carbon footprint? A.) vegetables, B.) legumes, nuts, and seeds, C.) grains and flour, or D.) meat.

Environmental Self-Efficacy Questions asked participants about how much they thought that their actions impacted the environment. For example: Please select your level of agreement for each of the following statements (1-5: Strongly Disagree, Disagree, Neither Agree nor Disagree, Agree, Strongly Disagree): My personal choices affect the environment.

Reactions to the Training Questions asked participants to rate the training and asked several open-ended questions about possible improvements to the training for future use.

Intentions Questions asked participants about how and in what way they intended to use the information from the Training and Behaviors Questions asked participants how they actually did use the information from the training. For example: Please select your level of agreement for each of the following statements (1-5: Strongly Disagree, Disagree, Neither Agree nor Disagree, Agree, Strongly Disagree): I plan to use the information I learned in this training next time I am shopping for food. 